\title{
Desafios do ensino de Ciências para alunos surdos
}

\author{
Challenges of Science teaching for deaf students \\ Desafíos de la enseñanza de las Ciencias para estudiantes sordos
}

Recebido: 17/09/2021 | Revisado: 26/09/2021 | Aceito: 02/10/2021 | Publicado: 03/10/2021

\author{
Rosemary Meneses dos Santos \\ ORCID: https://orcid.org/0000-0003-1620-9653 \\ Universidade Federal do Delta do Parnaíba, Brasil \\ E-mail: rosemarymeneses2009@gmail.com \\ Silvana Maria de Oliveira Brito \\ ORCID: https://orcid.org/0000-0003-1928-7825 \\ Universidade Federal do Delta do Parnaíba, Brasil \\ E-mail: sylvanabrito@hotmail.com \\ Raí Emanuel da Silva \\ ORCID: https://orcid.org/0000-0002-4266-0475 \\ Universidade Federal do Piauí, Brasil \\ E-mail: raiemanuel@ hotmail.com \\ Denis Sousa Melo \\ ORCID: https://orcid.org/0000-0001-9083-4567 \\ Secretaria de Estado de Educação do Maranhão, Brasil \\ E-mail: denis.melo@hotmail.com \\ Ernandes Barbosa Gomes \\ ORCID: https://orcid.org/0000-0002-6647-1281 \\ Secretaria Municipal de Educação de Tutóia-MA, Brasil \\ E-mail: ernandesb.gomes@gmail.com
}

\begin{abstract}
Resumo
Na promoção da educação para surdos, é importante pensar e organizar um ensino que lhe garanta participação plena, fazendo uso de sua língua dentro do recinto da sala de aula, e dos demais espaços escolares. Desta forma, abordar o ensino de Ciências a alunos com surdez se fez necessário, de modo a mostrar como o ensino vem sendo desenvolvido, bem como se a inclusão está atendendo às características linguísticas de aprender. O presente estudo teve como objetivo analisar os desafios do ensino de ciências para alunos surdos em duas escolas públicas pertencentes a rede estadual de ensino do Piauí, na modalidade do ensino médio. Por meio de uma pesquisa exploratória, com abordagem qualitativa, realizou-se um relato das experiências vivenciadas na disciplina de estágio supervisionado no primeiro ano do ensino médio, juntamente com uma revisão da literatura, de modo a se explanar sobre o tema e compreender tal relação. Neste sentido, utilizou-se os descritores inclusão, ensino, aprendizagem, formação pedagógica, estratégias, recursos visuais e gestuais. Os resultados inferem que, apesar da existência de leis que assegurem o direito ao ingresso à escola e à educação, estas não são as únicas garantias que tornam possível a qualidade do ensino aos estudantes surdos. Foi verificado ainda que se faz necessário rever a presença de professores despreparados para a ação da inclusão, escassez de alguns sinais em Libras que expressem as temáticas em ciências, bem como a promoção da formação continuada de professores em Libras, além da estruturação de escolas não bilíngues.
\end{abstract}

Palavras-chave: Ensino de ciências; Surdos; Professor; Formação em Libras.

\begin{abstract}
In promoting education for the deaf, it is important to think about and organize education that guarantees full participation, making use of their language within the classroom and other school spaces. Thus, approaching the teaching of Science to deaf students was necessary, in order to show how teaching has been developed, as well as whether inclusion is meeting the linguistic characteristics of learning. This study aimed to analyze the challenges of teaching science to deaf students in two public schools belonging to the state education system of Piauí, in the modality of high school. Through an exploratory research, with a qualitative approach, an account of the experiences lived in the supervised internship discipline in the first year of high school was carried out, together with a literature review, in order to explain the topic and understand this relationship. . In this sense, the descriptors inclusion, teaching, learning, pedagogical training, strategies, visual and gestural resources were used. The results infer that, despite the existence of laws that ensure the right to enter school and education, these are not the only guarantees that make quality education possible for deaf students. It was also found that it is necessary to review the presence of teachers who are unprepared for the action of inclusion, the scarcity of some signs in Libras that express the themes in science, as well as the promotion of continuing education of teachers in Libras, in addition to the structuring of schools that do not bilingual.
\end{abstract}

Keywords: Science teaching; Deaf; Teacher; Training in Libras. 


\begin{abstract}
Resumen
En la promoción de la educación para sordos, es importante pensar y organizar una educación que garantice la participación plena, haciendo uso de su lengua dentro del aula y otros espacios escolares. Así, era necesario acercar la enseñanza de las Ciencias a los estudiantes sordos, con el fin de mostrar cómo se ha desarrollado la enseñanza, así como si la inclusión está cumpliendo con las características lingüísticas del aprendizaje. Este estudio tuvo como objetivo analizar los desafíos de la enseñanza de la ciencia a estudiantes sordos en dos escuelas públicas pertenecientes al sistema educativo estatal de Piauí, en la modalidad de bachillerato. A través de una investigación exploratoria, con un enfoque cualitativo, se realizó un relato de las experiencias vividas en la disciplina del internado supervisado en el primer año de bachillerato, junto con una revisión de la literatura, con el fin de explicar el tema y comprender esta relación. En este sentido, se utilizaron los descriptores inclusión, enseñanza, aprendizaje, formación pedagógica, estrategias, recursos visuales y gestuales. Los resultados infieren que, a pesar de la existencia de leyes que aseguran el derecho al ingreso a la escuela y la educación, estas no son las únicas garantías que hacen posible una educación de calidad para los estudiantes sordos. También se encontró que es necesario revisar la presencia de docentes que no están preparados para la acción de inclusión, la escasez de algunos signos en Libras que expresan los temas en ciencia, así como la promoción de la formación continua de docentes en Libras, además de la estructuración de escuelas que no sean bilingües.
\end{abstract}

Palabras clave: Enseñanza de las ciencias; Sordo; Maestro; Entrenamiento en Libras.

\title{
1. Introdução
}

O presente trabalho, mostra conhecimentos do ensino de Ciências no primeiro ano do ensino médio, especificamente o estudo da célula. Dentre tantos conteúdos ministrados, é necessário repensar a forma como ensinar e desenvolver estratégias eficazes ao processo de aprendizagem dos surdos, instigando ainda a reflexão da ação pedagógica das escolas públicas inclusivas, visando a promoção do conteúdo ao aluno que traz distinção de aprendizagem e que precisa de ferramentas mais visuais e sinalizadas. A partir do conteúdo aqui estudado e observado pelos pesquisadores, percebe-se que a inclusão é um fato, que mesmo sendo assegurado a todos em condições acessíveis ao ensino, mensura-se que a inclusão aos surdos no recinto da escola pública, precisa passar por alterações nas práticas pedagógicas e discussões sobre a obrigação do país em oferecer um ensino de equidade, em suas propostas educacionais, conforme a funcionalidade a peculiaridade de aprender do aluno surdo. Além disso, é importante compreender os desafios no ensino regular quanto ao processo metodológico, recursos, práxis e estratégias que estão sendo utilizadas no ensino comum público.

Para Quadros (2015), o objetivo da inclusão é garantir que todos tenham igualdade de oportunidades e tenha como pretensão, evitar a exclusão, o isolamento social e cultural. Falar da inclusão das pessoas surdas no ambiente escolar promove nas crianças o respeito pelas diferenças, demostrando que todos são iguais diante das legalidades de oportunidades aos serviços sociais, bem como possuem capacidade de assimilar conteúdos, considerando suas limitações e o respeito às suas necessidades. Para Dorziat (2004, p. 1), "tratar sobre a inclusão sem considerar as possibilidades de desenvolvimentos dos indivíduos e de sua participação como cidadãos, não passa de retórica".

Para promover a aprendizagem, o professor como base direta nesta ação, precisa conhecer, compreender e desconstruir metodologias que em muitos momentos podem não ser coerentes com a necessidade do aluno, em especial quando seu aluno é surdo. Dentre do espaço escolar, já foram notadas algumas barreias que comprometiam a aquisição do ensino ao surdo, dentre elas menciona-se: a inexistência de comunicação através de sinais dentro do espaço escolar, o despreparo do professor que trabalha com o aluno surdo, a aplicação de metodologias não condizentes com o modo de percepção e aprendizagem do aluno, ausência de usar a Língua Brasileira de Sinais (Libras) como meio de comunicação e expressão, práticas, estratégias de maneira visuais e em Libras. Com base nestas supracitadas questões, instigou ao seguinte questionamento: os professores estão conseguindo oferecer estratégias acessíveis no processo de ensino-aprendizagem de Ciências aos alunos surdos?

Diante desta inquietude, Queiroz, Silva, Macedo \& Benite (2012), aduzem que é importante compreender que a presença do surdo no ensino regular solicita uma educação bilíngue, com melhores condições à sua condição de sujeito, 
necessitando de professores surdos ou intérpretes em sala de aula com metodologias e materiais voltados à sua realidade. Encara-se ainda que os alunos surdos precisam ter acesso precocemente a sua língua, para assim desenvolver melhor suas habilidades linguísticas, o que torna a Libras primordial na construção do aprendizado. Neste sentido, acrescenta-se ainda que o professor pode fazer uso de outros recursos que venham somar com o ensino na forma peculiar de aprender.

De acordo com Perlin e Strobel (2014), pode-se relatar o quanto a presença e a formação inicial e continuada dos professores e intérpretes no ensino de Ciências necessita ser mais estimulada. Isso pode se materializar com a disponibilização, ainda na graduação, de uma carga horária maior da disciplina de Libras, dividida em etapas, tais como: uma etapa introdutória, uma etapa com práticas em sala, e uma terceira etapa com estágio nas escolas regulares e oficinas de modelos didáticos específicos da disciplina. Nesta última, é importante considerar o uso de recursos pedagógicos visuais que envolvam a utilização de imagens como método de ensino, bem como oriente o futuro docente em como deve agir diante de seus alunos surdos.

O interesse de se argumentar como é aplicado o ensino de ciências é decorrente do fato da inclusão nas escolas públicas ser uma realidade que se contrapõe aos parâmetros que a orientam. Essa contraposição se materializa pela falta de estrutura das escolas públicas, bem como pelo despreparo de professores em relação às metodologias empregadas no ensino de alunos surdos. Com base nisso, Oliveira e Benite (2015) defendem que a integração da pessoa surda na educação, no ensino regular, é um desafio a ser enfrentado por educadores, pela sociedade de modo geral e exige trabalho, mudanças de atitudes, força de vontade de todos, e também o apoio das políticas públicas para que realmente dê certo.

\subsection{Educação de Surdos no Brasil}

A busca por uma educação que permita ao surdo ter acesso, participar e se desenvolver com o uso de sua língua nas escolas, são questões que vem sendo refletidas cotidianamente, em todo território nacional entre pesquisadores, órgãos não governamentais, associações, comunidades e a própria pessoa surda. Isso acontece por isto ser uma necessidade marcante em todas regiões do país. Segundo Albres e Neves (2013), o atendimento no meio educacional ao cidadão surdo no Brasil, teve início na época do Império com a inauguração da primeira escola para surdos em 1857, no Rio de Janeiro, o Imperial Instituto dos Surdos Mudos, que atualmente é conhecido como Instituto Nacional da Educação de Surdos (INES).

Afirmam também que o uso da língua de sinais no INES foi difundido pelo professor surdo Eduard Huet, que tinha um projeto de educação que atendesse às necessidades dos alunos surdos, proporcionando a estes aperfeiçoar a linguagem e o conhecimento, além de uma base para que pudessem aprender a ler e escrever a língua majoritária da sociedade ouvinte. Para Strobel (2009), foi nesta escola que surgiu a Língua Brasileira de Sinais (Libras), resultante da mistura da língua de sinais francesa, com os sistemas já usados pelos surdos de várias regiões do Brasil.

Segundo Rocha (2009), o Instituto era de natureza mista, isto é, para meninos e meninas surdas. Era uma instituição privada e começou a funcionar no dia 01/01/1856, nas dependências do Colégio de M. De Vassimon, no Rio de Janeiro. Sendo que as meninas ficavam sobre a responsabilidade da "Madame de Vassimon e suas filhas" (Da Rocha, 2009, p. 38). A autora também afirma que a fundação da escola se institui pelo art. $7^{\circ}$ do decreto ${ }^{\circ} .6 .892$ de 19 de março de 1908, mas, $\log$ após, teve a transferência para o dia 26 de setembro de 1857, conforme descrição apresentada por Strobel (2009).

A comunicação gestual, reconhecida como Libras, segundo Rocha (2009), foi espalhada por todo o Brasil na gestão do Doutor Tobias Leite (1868/1896), no Imperial Instituto dos Surdos-Mudos de Ambos os Sexos. Isso aconteceu devido ao retorno de seus alunos aos seus locais de origem e também pela dispersão de algumas publicações feitas nesse Instituto. Como exemplo da distribuição de algumas publicações, a autora cita o trabalho produzido em 1875, por Flausino José da Gama, exaluno do Imperial Instituto de Surdos-Mudos, o livro Iconographia dos Signaes dos Surdos-Mudos. O livro continha o registro 
dos sinais (palavras) mais praticados pelos surdos na época. Este livro serviu para divulgar o meio pelo qual os surdos se comunicavam.

Continuando o pensamento da autora, o Imperial Instituto dos Surdos-Mudos era direcionado ao ensino profissionalizante e à educação literária de jovens surdos-mudos, incluindo meninas e meninos, com idade entre 7 e 16 anos, onde na instituição, o trabalho de articulação labial era destinado somente àqueles alunos que tivessem aptidão, o que desmistifica a história que o Instituto tinha tradição oralista, conforme observação feita pela autora.

Completando a elucidação anterior, Honora e Frizanco (2009) relatam que em 1951, pela primeira vez um profissional da educação assume a direção do Instituto, após quase 100 anos de existência, uma vez que durante sua gestão teve a implantação do Curso Normal de Formação de Professores para Surdos. Este durava três anos e a metodologia adotada era direcionada para o Oralismo. Os autores citam ainda que alguns órgãos de educação que fizeram parte da história das pessoas surdas, como por exemplo o Instituto Santa Terezinha (1929), a qual era dedicada inicialmente à educação de moças surdas, em regime de internato. A autora também relata que após a década de 1970 o instituto sofreu algumas transformações, começando a atender tanto meninos e meninas, não mais em forma de internato, mas, externato. Além do instituto Santa Terezinha, o Brasil teve outras instituições que tiveram grande importância para os surdos como a escola Municipal de Educação Especial Helen Keller (1952) em São Paulo, e o Instituto Educacional São Paulo (IESP), fundado em 1954, e incorporado à PUCSP - Pontifícia Universidade Católica de São Paulo em 1969. Todas sendo referências no tratamento de pessoas detentoras de distúrbios de audição, voz e linguagem.

Também no Brasil foi criado em 16 de maio de 1987 a Federação Nacional de Educação e Integração dos Surdos (Feneis), que trabalha na proteção dos direitos linguísticos e culturais da comunidade surda. Felizmente, apesar que de forma lenta, ao longo do tempo o surdo no Brasil foi sendo notado, juntamente com o surgimento de instituições de apoio. Adicionalmente, muitas conquistas foram alcançadas, mas estas representam apenas o início de uma grande jornada. Pode-se mencionar ainda, que no mês de junho de 2021, o Ministério da Educação, lança propostas curriculares para o ensino de Língua Portuguesa, escrita como segunda língua para estudantes surdos da Educação Básica e Ensino Superior (Dos Santos Lima \& Fernandes, 2021).

\subsection{Libras e o Bilinguismo}

A linguagem é essencial para a convivência e para a transmissão do pensamento, pois é por meio dela que o homem através do contato com outros de sua espécie consegue desenvolver suas habilidades, tendo este a capacidade de emitir sons ou não. Quando nos referirmos à pessoa surda para a aquisição de conhecimentos, sua linguagem, seu meio de interação é a língua brasileira de sinais, sendo assim essenciais para seu pertencimento no meio que o cerca. Assim, Da Silva (2015) corrobora que a linguagem, seja ela verbal ou gesto visual, permanecem como meio ideal para transmitir conceitos e sentimentos, além de fornecer elementos para expandir o conhecimento.

Segundo Kotaki e Lacerda (2011), a língua brasileira de sinais é uma língua viso-gestual utilizada por comunidades surdas brasileiras, que tem como função possibilitar as pessoas surdas a expressão de seus sentimentos, ideias, ações, além de estabelecer uma comunicação com as demais pessoas. Portanto, é considerada de extrema importância para as comunidades surdas, sendo assim o seu meio de contato com o mundo, com as pessoas a seu redor, e, portanto, possui grande impacto na construção de conceitos que possibilitam essa interação. Por ser uma língua que atende as necessidades de comunicação da pessoa surda, sua utilização no ensino aprendizagem promove ao surdo o seu desenvolvimento intelectual.

Em 24 de abril de 2002, a Língua Brasileira de Sinais, foi reconhecida pela Lei n. 10.436 como uma forma de expressão e comunicação da pessoa surda. Com isso, a inclusão do ensino de Libras pelos sistemas educacionais nos cursos de 
magistério tornou-se obrigatória (Müller, Stürmer, Karnopp, \& Da Silva Thoma, 2013). A lei é uma forma de garantir o atendimento $\mathrm{e}$ o tratamento adequado às pessoas com necessidades educacionais especiais.

De acordo com Carmozine e Noronha (2012, p. 51), a Libras é "Utilizada por uma maioria de surdos, e apresenta-se como a forma mais eficaz para que ocorra uma comunicação funcional entre surdos e entre surdos e ouvintes”. Portanto, encara-se que a Libras é imprescindível para a educação das pessoas surdas, representando assim a sua voz, através dos gestos das mãos, o seu meio de comunicação na comunidade surda e no mundo dos ouvintes. Desta maneira, a Libras representa o meio que lhes dá a possibilidade de fazer parte do regime inclusivo de ensino, promovendo desde a sua inserção no ambiente escolar até um futuro próximo, no seu ambiente de trabalho.

Uma ideologia de ensino que une Libras à língua portuguesa é denominada bilíngue. Sabe-se que esta filosofia de ensino defende o ensino de duas línguas, a língua portuguesa, esta, na forma escrita, considerada a língua oficial do país, e a língua de sinais, declarada como a segunda Língua do país. No Brasil, a educação bilíngue é amparada por Lei e é recomendada pelo Ministério Nacional da Educação (MEC), como sendo uma proposta eficaz para o ensino das duas Línguas, necessárias para a inclusão social do sujeito surdo, conforme o Decreto $n^{\circ} 5.626$ de 22/12/2005, que regulamenta a Lei $n^{\circ}$ 10.436/2002, em seu capítulo VI, artigo 22 (Lodi, 2013).

Na filosofia do Bilinguismo, a pessoa surda deve assumir sua condição de surdo como parte de sua identidade, não tendo que se adequar à realidade da comunidade ouvinte, imposição que muito ocorreu no passado, quando este era forçado a se utilizar da filosofia oralista. A pessoa surda deve viver sua realidade, mas ao mesmo tempo, fazer parte da comunidade que a rodeia, a comunidade ouvinte. O bilinguismo visa promover ao indivíduo o conhecimento e a eficiência em duas línguas, como já descrito acima, sua língua materna e a língua de seu país (Português), sendo esta última aprendida na forma escrita, que representa um requisito imprescindível para que o estudante surdo possa participar da aula, compreender e ser compreendido. Para Quadros (2015), a questão da inclusão da Libras/Português em sala de aula, implica transformação na estrutura dos espaços, procedimentos metodológicos, nos instrumentos, interação e formações dos atores de propocionar o ensino e mediar o conhecimento, ou seja, os professores e intérpretes.

Tal filosofia permite que uma Língua auxilie a outra, proporcionando a inserção da comunidade surda junto à comunidade ouvinte e vice-versa. Logo, para que se tenha uma educação que traga resultados satisfatórios, a língua de sinais deve ser estudada o mais cedo possível, por ser considerada a primeira língua dos surdos e, somente depois, o português como segunda língua. Mas infelizmente esse ensino é tardiamente ofertado pelos pais, que em sua maioria são ouvintes, o que acarreta a criança surda não adquirir nem sequer o domínio da Libras, apresentando, portanto, um atraso no desenvolvimento cognitivo. Porém, na concepção de Silva e Souza (2015, p. 21) "percebemos que houve várias mudanças, mas ainda falta muito a alcançar no sentido da efetivação das políticas dentro das escolas".

Segundo Menezes (2020), para o aluno surdo é um árduo esforço acompanhar a rotina das aulas, como exemplos: exposição oral, cópia de texto, resolução de exercícios, atividades individuais e/ou coletivas. A presença de uma educação bilíngue nas escolas com o contato com a Libras pode permitir-lhes um novo modo de compor as relações escolares. Para que ocorra a Educação nesta filosofia, é necessário não só o domínio do surdo em Libras, se faz essencial também que este tenha o contato com o Português, para a evolução da leitura e da escrita, além de se tornar mais fácil as demais diretrizes curriculares. Pode-se mencionar entre tantas o ensino de Ciências, tão essencial à língua mãe.

De acordo com Carmozine e Noronha (2012, p. 42) "o bilinguismo é uma das propostas mais adequada ao processo de ensinar e desenvolver o aprendizado das crianças surdas, respeitando suas diferenças linguísticas e lhes dando autonomia”. Encara-se que por meio desta modalidade de ensino, as atividades propostas devem atender suas características educacionais com vistas ao desenvolvimento pleno das suas capacidades e o professor de Ciências precisa, desde da sua formação inicial e continuada, ter conhecimentos da inclusão, além de manter-se curioso, pesquisador e compreender que sua sala de aula é um 
contexto diversificado de alunos, cada um com características únicas de aprender. Completando o entendimento Câmara (2020) ratifica a relevância de reconhecer as diversidades sociais, linguísticas, econômicas culturais, e suas implicações para efetivar a participação desses alunos no âmbito educacional.

A educação bilíngue é necessária e indispensável para a pessoa surda, já que esta filosofia respeita a estrutura da Libras e da Língua Portuguesa. Por isso com o aprender de ambas línguas na infância pela criança surda, esta não vai enfrentar muitas dificuldades no tocante ao aprendizado das diversas disciplinas ao ingressar em uma rede regular de ensino. Além da transmissão de conhecimentos e experiências que poderão ser construídas de forma recíprocas não apenas ao surdo, mas, aos não surdos.

Considera-se de grande significância analisar os desafios do ensino de ciências para alunos surdos. Diante disso, o estudo teve como objetivos específicos descrever a realidade dos procedimentos metodológicos utilizados pelos professores no ensino de ciências, e apresentar se existe o uso de recursos que favoreça o processo de ensino e aprendizagem nas aulas de ciências para alunos surdos. Com isso, os dados foram obtidos através da observação sobre as práticas e estratégias aplicadas por professores no repasse dos temas envolvidos na disciplina. Adicionalmente, realizou-se em paralelo uma revisão de literatura integrativa, de modo a reunir as principais publicações científicas acerca do tema.

Para a execução deste trabalho, foi utilizada uma pesquisa exploratória descritiva, com relatos das experiências do cotidiano da sala de aula de duas escolas do Ensino Médio, especificamente no primeiro ano. Para alcançar resultados condizentes ao tema, os pesquisadores fizeram diversas revisões de acervo já publicados, que de acordo com Cervo, Bervian \& da Silva (2007), a pesquisa exploratória emerge os cientistas a desvendar conhecimentos, sejam de fontes bibliográficas ou em contexto empírico. Assim, para desenvolver um estudo cientifico, há necessidade de selecionar acervos coerentes e fundamentais a certificar cada conhecimento supracitado, dando ao trabalho validade e principalmente promover reflexões que possam instigar a outros saberes. Desta maneira a pesquisa se fundamentou em diversos autores, tais como: Dorziat (2004), Da Rocha (2009), Strobel (2009), Kotaki e Lacerda (2011), Perlin e Strobel (2014), Quadros (2015), Briega (2019), entre outros. Estes com temas focados na educação de surdos.

\section{Metodologia}

O artigo foi construído a partir de experiências de pesquisadores em diversas concepções educacionais, especificamente, no momento basilar de um dos pesquisadores ao ser inserido no recinto da sala de aula, ao cursar a disciplina de Estágio Supervisionado na Educação Básica (Ensino Médio), no curso de graduação em Ciências Biológicas, da Universidade Federal do Delta do Parnaíba-UFDPar, em 2019. Devido a isso, Estrela (2018, p. 4), aduz que "a ciência de educar e pesquisar é uma ação complexa e difícil de explicar em frases e palavras, há necessidade de vivenciá-las e estar aberta a mudá-las e construir novos conhecimentos".

Fazer pesquisa, é se colocar na condição constante de aprendiz, tendo a consciência que o conhecimento é construído a partir de investigações incansáveis, necessitando ler e reler, de modo a extrair o que for mais significativo. A construção de novos saberes é responsável em alimentar a humanidade e constituir imunidades à ignorância. Nesta perspectiva, Menezes et al. (2019), comentam que a busca por conhecimentos a partir de um problema prático, ocasionará descobertas de saberes ainda não questionáveis, que poderá instigar reflexões cabíveis às transformações do ponto em estudo. Por essa razão, a pesquisa aconteceu durante um semestre, com o objetivo de selecionar o maior número de informações possíveis e relevantes aos desafios do ensino de Ciências para alunos surdos em duas escolas públicas pertencentes a rede estadual de ensino. As instituições estão localizadas nas cidades de Parnaíba e Luís Correia, litoral do Piauí.

O tipo de pesquisa utilizado foi do tipo exploratória com relatos de experiências descritivas, por meio de uma abordagem qualitativa, no qual exigiu observações criteriosas de cada momento. Para Victorino (2018), ao utilizar a 
observação como fonte de levantamento de dados, o pesquisador precisa ser crítico diante dos fatos e de cada fenômeno que acontece na escola, pois ela possibilita uma extensão de dados, além das perspectivas previstas pelo pesquisador.

Todos os dados foram observados e analisados segundo as vivências, quanto a metodologia utilizada pelos professores em suas funções na disciplina de Ciências no Ensino Médio. Segundo Yin (2016), a pesquisa qualitativa é um campo multiforme de investigação com diferentes orientações e metodologias, e que ela permite uma realização de estudos aprofundados, que têm como características o conhecimento, o saber da vida real das pessoas pesquisadas, a representação de suas opiniões e perspectivas, em que o estudo pode ajudar a explicar o comportamento social humano.

Para construir a pesquisa e apresentar uma reflexão sobre o tema, realizou-se adicionalmente, uma revisão de literatura. As revisões de literatura representam um estudo baseado em publicações científicas já disponíveis na comunidade científica, tais como artigos científicos publicados em periódicos nacionais e internacionais, bem como livros, monografias, dissertações e teses (Prodanov, 2013). Para alcançar esta segunda parte do estudo foram utilizados os descritores: Ensino de Ciências; Surdos; Professor; Formação em Libras. Para certificar o estudo, os pesquisadores debruçaram-se em selecionar acervos de teóricos clássicos e modernos, disponibilizados nas plataformas científicas; SciELO, Google Acadêmico, periódicos da CAPES, Biblioteca digital de teses e dissertações. Ressalta-se que trabalhos na área de Ciências a alunos surdos são escassos, obtendo-se em cada plataforma um total de até 10 artigos envolvendo o tema estudado.

\section{Resultados e Discussão}

Nesta etapa, apresenta-se as experiências vivenciadas no formato de categorias: conhecimentos sobre a Libras, estratégias, desafios e soluções de como ensinar e promover uma educação inclusiva/bilíngue na prática didática do professor.

\subsection{Conhecimento e utilização da Libras por professores e alunos surdos}

Pesquisas tem mostrado conquistas, desafios e lutas de implementar a língua de sinais no contexto social e educacional. A Libras por ser uma língua de modalidade gestual-visual, reconhecida por lei no Brasil como a língua natural das pessoas surdas, torna-se essencial para haver acessibilidade de comunicação entre surdos/surdos e surdos/ouvintes. Porém há peculiaridades que precisam ser conhecidas por quem fizer uso da mesma. De acordo com Victorino (2018), tais peculiaridades envolve os contextos histórico, cultural e o dia a dia dos surdos, diante do meio inserido. Todavia, no processo de inclusão educacional do aluno surdo, a Libras é uma ferramenta indispensável no processo de ensino-aprendizagem em Ciências. Nesta concepção, Santos, França, Rodrigues, Silva e Barros (2021, p. 62298) trazem que:

É sabido o quanto a diversidade de alunos se faz presente no contexto escolar, colocando a instituição a se reinventar, desconstruir e construir um novo espaço educacional, que favoreça a construção pessoal e social de seus alunos, tornando-os seres ativos, críticos, participativos e conscientes de seu papel na sociedade.

Em resposta ao supracitado contexto, foi observada a carência por parte do professor em conhecer e de usar os sinais em Libras durante as exposições dos temas na sala de aula, em específico ao ensino das células. Mas, os alunos surdos utilizavam a língua de sinais para dialogar com seu intérprete. Foi observado ainda que os discentes surdos das duas instituições não têm o domínio de sua língua mãe (Libras) e nem da língua portuguesa, tal situação prejudica o aprendizado, tornando mais difícil a compreensão pelos alunos nos temas relacionados ao ensino de Ciências, bem como nas diversas disciplinas. Quadros (2015, 2018), Skliar (2005), Victorino (2018), mencionam que não ter o domínio de sua língua, não significa que o aluno surdo não consiga assimilar os conteúdos, significa que o aprendizado torna-se mais demorado.

Fica uma incógnita diante do mencionado anterior, como desenvolver uma aula de Ciências ao educando surdo se o professor regente não tem firmado o ato da comunicação? É importante o entendimento da língua de sinais pelos professores 
da educação inclusiva e por seus alunos surdos, visando um maior diálogo entre eles. Pois sem o ato da comunicação não vai existir a aquisição do conhecimento. Na visão de Victorino (2018), a rotina de uma escola enfrenta diversos desafios. Ela enquanto instituição de educação formal, é um local marcante na vida do surdo, se ela não está com as condições acessíveis de estrutura pedagógica, profissionais qualificados as reais necessidades do aluno, como será o aprendizado? Com esta inquietude nas aulas, tornaram-se claros os diversos momentos de não inclusão quanto à ação de educar do professor de Ciências e o aluno surdo. Dentro desse contexto, suas práticas eram pensadas e organizadas aos alunos não surdos, visualizando com estas atitudes um ensino excludente.

Segundo Leite (2016, p. 6 e 7), "dar a todos o mesmo", significa não promover a inclusão, pois todos somos diferentes. Assim, dentro desta condição singular de cada aluno, é que o ensino deve ser diferente, ou seja, deve-se utilizar de diferentes metodologias, estratégias, recursos e matérias, principalmente visuais, para oportunizar a equidade. Por isso, "pensar a partir do que se recebe e não a partir daquilo que se dá", bem como não promover o ensino com atenção as reais necessidades da turma, tudo não passará de falácia e utopia. Os teóricos Quadros $(2015,2018)$, Perlin e Strobel (2014), ratificam que há necessidade dos professores elaborarem atividades que valorizem os aspectos singular das pessoas surdas.

No presente estudo foi notado também a carência das escolas em respeitar a diversidade de seus alunos em seu ato de aprender. Nas observações e vivência no recinto escolar e na sala de aula, pode-se constatar a necessidade por parte docente em aprender a nova língua (Libras), sendo este um instrumento a ser utilizado em todas propostas didáticas em sala de aula, e nos demais espaços escolares. Claro que ter um professor fluente na língua era e é necessário. Mas enquanto isso não acontece, espera-se que eles sejam responsáveis pela educação, e estejam conscientes que sua ação precisa se apropriar de todas as ferramentas que lhes permitam dar aos alunos surdos o conhecimento, de maneira que este possa aprender e se desenvolver a partir de sua Língua natural. Para Leite (2016), as escolas desde o princípio do século XIX até o atual momento, não são universais em termo de ofertar um currículo que atenda a todos nas suas mais variadas percepções de aprender.

Ainda para o autor citado, diante da ausência do conhecimento da segunda língua oficializada pela Lei 10.436/24/2002 e regulamentada pelo Decreto 5.626/2005, a escola precisa se mobilizar e oferecer aos seus professores formações diante da necessidade da turma, e quando a instituição não ofertá-la, cabe o docente buscar e não esperar pelos órgãos competentes. Pois, quanto mais conhecimento diante da diversidade de alunos em sua condição de aprender, melhor será suas práxis. Por conseguinte Araújo, Menezes e Araújo (2017, p. 200) trazem que "a educação inclusiva no Brasil é marcada por preconceitos, lutas e conquistas". Neste sentido, as duas escolas estão longe de dizer que são inclusivas, pois em suas estruturas pedagógica e humanas, tantos os professores como demais profissionais carecem de orientações, formações e oficinas da língua de sinais, para assim promover um ambiente vivo nos dois idiomas do Brasil.

Para Albres e Neves (2013, p. 42), "pensar a educação de surdos requer, minimamente, pensar os caminhos pedagógicos, suas intervenções e mediações que ocorrem nos espaços que atendem surdos, em diferentes níveis de escolaridade". Por isso as instituições que promovem a inclusão devem oferecer cursos aos professores para que iniciem o contato direto com a Libras. Só assim professor e aluno surdo exercerão suas funções no ambiente escolar, de ensinar e de apreender, respectivamente, com trocas de experiências únicas às suas características, embora grandiosas para a construção de habilidades e competências diante da Libras e de valorização do sujeito surdo. Seguindo a visão dos teóricos, Pinheiro \& Rosa (2016) colocam que é relevante ressaltar que o aluno surdo pertence a um grupo com cultura distinta e com uma língua própria, que tem uma visão de mundo diferente dos ouvintes. Neste sentido, ressalta-se a importância dos professores saberem quem são seus alunos e como eles aprendem, sendo assim relevante conhecer as dificuldades enfrentadas pelos docentes no ambiente escolar. 


\subsection{Problemas enfrentados pelos professores no processo de Ensino-Aprendizagem de Ciências para aluno surdo}

Com a inclusão educacional de pessoas com deficiências, ensinar alunos surdos exige do professor conhecimentos de Libras e habilidades para lidar com suas necessidades educacionais especiais. Portanto, necessitam ter conhecimento sobre sua cultura, incluindo sua língua, suas crenças, costumes e hábitos, e quando esse conhecimento envolve o ensino e aprendizagem de Ciências, o ato de ensinar necessitará de leituras para conhecer e aprender estratégias visuais que supra a falta da língua sinalizada. Ressalta-se ainda que pela disciplina possuir em seus conteúdos muitos termos específicos, seu processo de ensinoaprendizagem se torna ainda mais complexo, e esta complexidade envolve a ruptura de concepções de não ter vivenciado em sua graduação o ensino da língua de sinais, necessitando desta maneira de outro profissional especializado a trabalhar com o aluno.

Dentre as complexidades no ato de ensinar, os educadores de Ciências demonstraram enfrentar diversos problemas. O dinamismo, uso de metodologias, recursos e formação, estão entre os fatores apontados por estes profissionais, refletindo desta forma em não saberem como executar o processo de ensino e promover a aprendizagem da disciplina aos alunos surdos, a ausência de formação específica em Libras, pouca ou nenhuma comunicação com sinalização, falta de materiais que envolva imagens, sinais e outros recursos visuais, são ainda elementos que dificultam tal abordagem. Em diálogo, os professores mencionaram ainda não terem cursos que lhes auxiliem para trabalharem com os alunos surdos, uma vez que a escola não oferta tais ferramentas, lançando mão do único material a ser utilizado, o livro didático. Sabendo que a Libras possui um status de língua, Cicilino, Giroto e De Vitta (2018), colaboram que a Libras promoverá ao surdo seu processo de escolarização, assegurando a apropriação dos conhecimentos pela escola e dando a ele o acesso ao currículo, à uma educação de equidade e qualidade aos bens culturais sociais valorizados. Desta maneira, encara-se que não são mais aceitas tais condições, em que se encontram as escolas regulares diante da forma de aprender do aluno surdo.

Diante das respostas, fica claro que a dificuldade dos professores observados é a falta de formação para lidar com os alunos surdos. Segundo Schinato e Strieder (2020), os professores quando são inseridos em um local bilíngue, não específico a área de Ciências, encontram-se despreparados para assumir a função, pelo fato de muitos relatarem não terem a preparação específica em sua formação acadêmica. Neste sentido, torna-se necessário que o professor procure fazer pesquisas referentes ao processo de ensino-aprendizagem da pessoa surda, para se inteirar de como interagir com seu aluno surdo. Além disso, a obtenção de informações com o intérprete que irá trabalhar com o discente surdo também traz benefícios a esta relação. Para Glat, Pletsch e Fontes (2009), ao realizar um ensino inclusivo é preciso de reestruturação e apropriação de diversos paradigmas legais. É fundamental rever o processo de formação dos professores, que em quase sua totalidade não tiveram um currículo direcionado aos alunos com deficiências no intuito de analisar as práticas pedagógicas voltadas a este público.

Além do professor não possuir conhecimento suficiente da língua da pessoa surda, materiais de ensino voltados para o público surdo ainda são escassos. Segundo Santiago (2014, p. 11), “pesquisas que contemplem o ensino de Ciências para surdos são escassas, as que abordam esse tema têm mostrado que professores têm encontrado diversos empecilhos na mediação de conceitos". Lamentavelmente ainda são poucos os materiais pedagógicos desenvolvidos para o ensino de Ciências voltados para comunidade alvo presente estudo. Tal situação faz com que professores sintam dificuldades em oferecer um ensino de qualidade. Seguindo o pensamento, Alves (2019) argumenta que quando o professor se depara na classe comum com alunos surdos, apresentam dificuldades, e estas interferem tanto no processo metodológico como também na não valorização das características pessoais de aprender, criando entre eles barreias pedagógicas e humanas, que levam o professor em muitos momentos a se sentir desmotivado, não conseguindo criar alternativas de práxis.

Assim, mencionam-se alguns materiais que podem ser úteis na explanação de temas em Ciências e que devem ser utilizados pelos professores, servindo a todos os alunos, seja ele surdo ou ouvinte. São os chamados elementos imagéticos, tais como: maquetes, desenhos, gráficos, fotografias, vídeos, aplicativos, etc. O docente necessita ter a sabedoria de saber utilizá- 
los no momento do planejamento de suas aulas, focando no ensino de todos os alunos, com observação em suas necessidades. Para Quadros (2018) é extremamente importante uma interação eficaz entre os diferentes atores educacionais, para organizar formas colaborativas de planejamentos, atividades e avaliações conjuntas.

Desse modo, é importante que o profissional que atuará na educação inclusiva/bilíngue no ensino de Ciências, tenha noção das necessidades educacionais de seus alunos surdos, possibilitando no seu ensino a inserção de metodologias e estratégias existentes que venham facilitar e garantir a apreensão do conhecimento pelo discente. Na falta desses recursos, com pesquisas e com o auxílio do intérprete e outros profissionais que atuam com Libras, é possível criar um elo entre eles, construindo juntos procedimentos metodológicos apropriados ao aprender do aluno.

\subsection{Solução proposta pelos docentes em relação as dificuldades no aprendizado de Ciências ao aluno surdo}

A falta da compreensão da língua falada, o atraso no aprendizado da Língua Brasileira de Sinais e a inclusão tardia na instituição de ensino são algumas das questões que dificultam o aprendizado do aluno surdo. Diante desses obstáculos, os professores aduzem que o visual é a melhor estratégia, bem como a utilização de pôsteres, materiais mais concretos, data show, vídeos, aulas passeio, cartazes, mapas, maquete, atividades em grupo, pesquisas coletivas, entre outros. Desta forma, Lacerda e Santos (2014) corroboram que em uma escola inclusiva motivar seus professores pela busca de novos saberes é essencial, pois a capacitação será uma ferramenta primordial de reconstruir práticas condizentes ao seu público atendido, trazendo para suas aulas novas estratégias e recursos que visem a ampliação sensorial e tátil dos alunos com surdez, favorecendo a aprendizagem.

Diante das possibilidades mencionadas, todas são significativas, mas ressalta-se que durante as aulas, entre os recursos citados, só foi observada a projeção de slides em data show. Entretanto, esse recurso não foi pensando no aluno surdo, uma vez que sua organização continha mais textos e poucas imagens. Segundo De Lacerda, Santos e Caetano (2011, p. 105), "o elemento imagético, tais como gráficos, uma fotografia, vídeos, trechos de filmes", pode-se tornar um material engrandecedor para o tema em estudo e principalmente para o aprendizado do aluno com surdez.

No ensino de Ciências, Física, Biologia, Química, Geografia e demais disciplinas, o professor precisa se apoderar de recursos que sejam condizentes a forma de aprender do aluno, como uma maneira de diminuir as dificuldades encontradas no ensino de Ciências. Além disso, se a escola tiver a presença do intérprete, os dois profissionais devem ter uma aproximação, pois ambos possuem suas incumbências, e são responsáveis pelo o aluno. Completando este entendimento, Rocha, Moretti, Costa e Costa (2015) ratificam que "é preciso ter dedicação, paciência e criatividade para estimular as potencialidades destes alunos". Promover a educação, não é e não será uma ação fácil, mas, nunca impossível. Todavia, precisa despertar na escola e seus colaboradores o respeito as diferenças de aprender de seus alunos.

O professor precisa usar a criatividade, ter ideias no planejamento de suas aulas, bem como buscar além dos recursos visuais, novos recursos e metodologias diferenciadas para garantir a compreensão dos diversos conceitos científicos provenientes das diversidades de temas contidos na disciplina de Ciências. Por fim, acrescenta-se ainda a possibilidade de ser pesquisador e construtor de metodologias capazes de ofertar o ensino com qualidade. Outra estratégia elencada pelos professores com maior frequência em seus discursos, foi a importância da escola em motivar seus professores com grupos de estudos, cursos de curta duração na área, construção de projetos que envolva todos no aprendizado da Libras, oficinas de modelos didáticos, tecnológicos, uso de aplicativos. Dos Santos, Assis e Baluz (2021), abordam que diante da diversidade que vive o contexto da sala de aula, o professor precisa dinamizar seus conhecimentos e práxis que possam "trazer ao ensino uma perspectiva de uma educação inovadora, instigadora e inquietante, a despertar o interesse dos alunos".

Contribuindo nesta concepção, Fernandes (2011) comenta da relevância dos materiais didáticos serem ferramentas cruciais na ação de ensino-aprendizagem, dependendo das estratégias, metodologias e organização de maneira inovadora na 
sala de aula, podem facilitar e promover a interação, comunicação e eliminar as dificuldades, quebrando as barreiras sociais e educacionais entre todos.

\section{Conclusão}

Como resposta ao objetivo geral que visou analisar os desafios do ensino de ciências para alunos surdos, ficou nítido um enorme desafio para os professores no ensino de Ciências para discentes surdos inclusos em classes regulares. Essa percepção foi possível ainda tendo por base a análise da argumentação feita pelos teóricos, as observações realizadas no ambiente escolar e as respostas obtidas de maneira espontânea pelos professores.

Pelo fato de vários aspectos presenciados durante o período em sala de aula como professora estagiária na escola, pode-se ressaltar o não domínio de Llibras e do português pelo aluno surdo e de Libras pelo professor. Destaca-se ainda a falta do conhecimento das reais necessidades educacionais do discente surdo pelos professores, bem como a dificuldade de se estabelecer práticas pedagógicas e estratégias específicas para o repasse de alguns conteúdos e termos específicos da disciplina de Ciências, visando o acolhimento das necessidades educacionais dos discentes surdos e ouvintes, simultaneamente. No momento em sala, onde estava sendo explanado o conteúdo específico da aula, foi nítido a carência de materiais e sinais realizados pelos intérpretes que promovessem e facilitasse o entendimento do assunto pelo aluno.

Outro fator que prejudica o aprendizado dos temas em Ciências é o desconhecimento e a inexistência de alguns sinais que fazem referência aos conteúdos envolvidos na disciplina. Um outro agravante é a aquisição tardia do ensino de libras pelo aluno surdo, prejudicando seu aprendizado. Nesse contexto reflete-se que o desenvolvimento de uma educação acessível a todos é valioso no repasse do conhecimento da disciplina e a utilização de estratégias que promovam uma participação mais ativa do aluno surdo, se faz necessária para que assim este sinta-se integrado no ambiente de ensino.

Os professores precisam estar em sintonia para desta forma construir o planejamento do material a ser aplicado ao estudante surdo. Essa sintonia envolve o intérprete na construção de propostas pedagógicas junto ao seu trabalho, criando uma parceria em prol do aprendizado do discente, sem deixar de lado o preparo deste profissional antes da aula, que deve ter conhecimento do conteúdo que será ministrado. Acrescenta-se ainda que estes devem estar atentos às novidades relacionadas ao surgimento de novos instrumentos de ensino e de novos sinais relacionados a linguagem científica de Ciências.

O ideal é que na escola tivessem materiais de apoio, como livros com imagens e sinais de termos na área, promovendo, desse modo uma aprendizagem mais rápida dos sinais já existentes. Mais o importante ainda seria que discentes ouvintes e surdos tivessem desde cedo acesso à disciplina de Libras, tornando esta sua língua natural, assim como o Português. Da mesma forma, o acesso a tal conteúdo no curso de graduação, permitiria aos futuros professores terem noções dos sinais em Libras, o que promoveria a seus futuros discentes surdos a interação educador/aluno, bem como também proporcionaria aos alunos surdos e ouvintes o diálogo, ação importante no ambiente escolar.

Diante do exposto, acredita-se que esta pesquisa seja o início de novas produções cientificas, apresentando a real situação que vive o surdo no ensino regular. Além disso, destaca-se ainda que este necessita não apenas de políticas públicas, mas, de maior empatia humana junto a ele no ambiente educacional, de modo a se garantir o acesso ao seu direito de estudar. Ressalta-se que mais estudos sejam desenvolvidos e direcionados ao ensino de Ciências, bem como às suas nuances na aprendizagem de alunos surdos, além de instigar reflexões da necessidade de práticas, estratégias, recursos visuais e professores que conheçam e desenvolvam em sua ação pedagógica bilíngue.

\section{Referências}

Albres, N. D. A., \& Neves, S. L. G. (2013). Libras em estudo: política educacional. FENEIS, 170.

Alves, R. D. (2019). Interações da criança pequena na educação inclusiva: contribuições para a educação de surdos. 
Araújo, A. S., de Carvalho Menezes, A. M., \& Araújo, A. C. S. (2017). A Educação de Surdos: Formação de Professores na Língua Brasileira de Sinais (LIBRAS). Id on line Revista de Psicologia, 11(38), 199-211.

Câmara, J. T. A. (2020). Escolarização de alunos surdos no cotidiano escolar. Revista Caparaó, 2(1), e17-e17.

Carmozine, M. M., \& Noronha, S. C. (2012). Surdez e Libras: conhecimento em suas mãos. Hub Editoriak.

Cervo, A. L., Bervian, P. A., \& Silva, R. (2007). Fases da pesquisa. O conhecimento científico. Bervian, PA \& Silva, R. Metodologia Científica, 6, 73-89.

Cicilino, J. E. M., Giroto, C. R. M., \& De Vitta, F. C. F. (2018). Formação de professores para a educação bilíngue de surdos na educação infantil e séries iniciais do ensino fundamental. Revista on line de Política e Gestão Educacional, 22(2), 794-809.

Da Silva, L. F. (2015). A linguagem como sinal diacrítico entre os ciganos na cidade alta. Revista Historiar, 7(12).

De Lacerda, C. B. F., dos Santos, L. F., \& Caetano, J. F. (2011). Estratégias metodológicas para o ensino de alunos surdos. Coleção UAB- UFSCar, 101.

De Quadros, R. M. (2018). A Língua Brasileira de Sinais (Libras): uma língua (Tese de Doutorado). Universidade Federal de Santa Catarina, Florianópolis, Santa Catarina, Brasil.

De Souza, C. T. R., Barbosa, M. O., \& Briega, D. A. M. (2019). Pesquisas em Educação Especial: Fios e Desafios. Appris Editora e Livraria Eireli-ME.

Dorziat, A. (2004). Educação de surdos no ensino regular: inclusão ou segregação? Revista Educação Especial, 77-85.

Dos Santos Lima, M. A., \& Fernandes, S. (2021). Identidades, Culturas E Diferenças: Desafios E Perspectivas Da Inclusão De Estudantes Surdos No Ensino Superior. Brazilian Journal of Development, 7(3), 28121-28137.

Dos Santos, R. M., da Silva França, V. C., Rodrigues, M. D. D. C. S., da Silva, R. V. S., \& de Morais Barros, R. (2021). No ensino médio? Construindo relatos e experiências no contexto do atendimento educacional especializado. Brazilian Journal of Development, 7(6), 62295-62305.

Dos Santos, R. M., de Assis, A. C. S., \& Baluz, R. A. R. S. (2021). Abordagens para uso da gamificação como metodologia ativa em ambientes virtuais de aprendizagem no ensino superior à distância. Research, Society and Development, 10(5), e4010514650-e4010514650.

Estrela, C. (2018). Metodologia científica: ciência, ensino, pesquisa. Artes Médicas.

Fernandes, S. (2011). Educação de surdos. Editora Ibepex,

Ferreira da Silveira, R. (2015). Desafios Das Crianças Surdas No Convívio Familiar, Escolar E Social. Encontro Internacional de Formação de Professores e Fórum Permanente de Inovação Educacional, 8(1).

Glat, R., Pletsch, M. D., \& de Souza Fontes, R. (2009). Panorama da educação inclusiva no município do Rio de Janeiro. Educação \& Realidade, 34(1), 123136.

Gomes, E. A., \& da Silva, W. S. (2018). Disposição espacial do intérprete e tradutor de Libras-Língua Portuguesa educacional no ensino superior sob a perspectiva do estudante surdo. Revista de Ciências Humanas, (2).

Honora, M., \& Frizanco, M. L. E. (2007). Ciranda da Inclusão; Esclarecendo as Deficiências. Ciranda Cultural.

Kotaki, C. S., \& Lacerda, C. B. F. D. (2011). O intérprete de língua brasileira de sinais no contexto da escola inclusiva: focalizando sua atuação na segunda etapa do ensino fundamental. Coleção UAB-UFSCar-Língua brasileira de sinais-Libras. São Carlos:[Sn].

Lacerda, C. B. F. D. (2014). Santos, Lara Ferreira dos, Caetano, Juliana Fonseca. Estratégias Metodológicas para o Ensino de Alunos Surdos. IN LACERDA, Cristina Broglia Feitosa de. SANTOS, Lara Ferreira dos. (Orgs.). Tenho um aluno Surdo, e agora, 185-200.

Leite, T. (2016). Formação de professores para a inclusão. In Congresso Internacional Escola Inclusiva-Educar e formar para a vida independente. CERCICA.

Lodi, A. C. B. (2013). Educação bilíngue para surdos e inclusão segundo a Política Nacional de Educação Especial e o Decreto n ${ }^{\circ} 5.626 / 05$. Educação e Pesquisa, 39, 49-63.

Menezes, E. N. T. D. (2020). Recursos didáticos para o ensino de língua portuguesa para surdos. (Trabalho de Conclusão de Curso). Instituto Federal da Paraíba, João Pessoa, Paraíba, Brasil.

Menezes, A. H. N., Duarte, F. R., Carvalho, L. O. R., \& Souza, T. E. S. (2019). Metodologia científica: teoria e aplicação na educação a distância. Universidade Federal do Vale do São Francisco, 83 p. Petrolina-PE.

Müller, J. I., Stürmer, I. E., Karnopp, L. B., \& da Silva Thoma, A. (2013). Educação bilíngue para surdos: interlocução entre políticas linguísticas e educacionais. Nonada: Letras em Revista, 2(21), 1-15.

Oliveira, W. D. D., \& Benite, A. M. C. (2015). Aulas de ciências para surdos: estudos sobre a produção do discurso de intérpretes de LIBRAS e professores de ciências. Ciência \& Educação (Bauru), 21, 457-472.

Perlin, G., \& Strobel, K. (2014). História cultural dos surdos: desafio contemporâneo. Educar em Revista, 17-31.

Pinheiro, R. C., \& Rosa, M. (2016). Uma perspectiva etnomatemática para o processo de ensino e aprendizagem de alunos Surdos. Revista Paranaense de Educação Matemática, 5(9), 56-83. 
Research, Society and Development, v. 10, n. 13, e39101320757, 2021

(CC BY 4.0) | ISSN 2525-3409 | DOI: http://dx.doi.org/10.33448/rsd-v10i13.20757

Prodanov, Cleber Cristiano. Metodologia do trabalho científico [recurso eletrônico]: métodos e técnicas da pesquisa e do trabalho acadêmico / Cleber Cristiano Prodanov, Ernani Cesar de Freitas. (2a ed.), FEEVALE, 2013.

Quadros, R. D. (2015). O “BI” em bilinguismo na educação de surdos. In: LODI, Ana Claudia Balieiro. et al. Letramento, bilinguismo e educação de surdos. (2a ed.), Editora Mediação, 187-200.

Queiroz, T. G. B., Silva, D. F., Macedo, K. G. D., \& Benite, A. M. C. (2012). Estudo de planejamento e design de um módulo instrucional sobre o sistema respiratório: o ensino de ciências para surdos. Ciência \& Educação (Bauru), 18, 913-930.

Rocha, L. R. M., Moretti, A. R., Costa, P. C. F., \& Costa, F. G. (2015). Educação de surdos: relato de uma experiência inclusiva para o ensino de ciências e biologia. Revista Educação Especial, 28(52), 377-392.

Rocha, S. M. (2009). Antíteses, Díades, Dicotomias No Jogo Entre Memória E Apagamento Presentes Nas Narrativas Da História Da Educação De Surdos: um olhar para o (Doctoral dissertation, PUC-Rio).

Santiago, N. C. (2014). O ensino e a aprendizagem das ciências dos alunos com surdez.

Schinato, L. C. S., \& Strieder, D. M. (2020). Educação Inclusiva no Campo da Pesquisa no Ensino de Ciências. HIPÁTIA-Revista Brasileira de História, Educação e Matemática, 5(1), 168-185.

Silva, J. M. D., \& Souza, N. B. D. S. (2015). A importância do bilinguismo no contexto escolar dos alunos surdos.

Skliar, C. (2005). Apresentação: um olhar sobre o nosso olhar acerca da surdez e das diferenças. A surdez: um olhar sobre as diferenças. Porto Alegre: Mediação.

Strobel, K. (2009). História da educação de surdos. UFSC.

Victorino, T. A. (2018). Ela não olha pra gente: o cotidiano escolar de jovens surdos no ensino médio. Dissertação de Mestrado. UFMG.

Yin, R. K. (2016). Pesquisa qualitativa do início ao fim. Penso Editora. 